\title{
Secondary Outcome Measure
}

National Cancer Institute

\section{Source}

National Cancer Institute. Secondary Outcome Measure. NCI Thesaurus. Code C98781.

Other key measures that will be used to evaluate the intervention(s) or, for observational studies, that are a focus of the study. These are the outcome measures used to assess the secondary objective(s). 